\title{
Hubungan Nilai Try Out dengan Nilai Computer Based Test pada Ujian Kompetensi Mahasiswa Profesi Pendidikan Dokter
}

\author{
Firdaus $^{1 *}$, Muhammad Rofi ${ }^{2}$, Elda Nazriati ${ }^{1}$
}

\begin{abstract}
The try out of UKMPPD is an effort to measure student's abilities and can provide an overview about competence that have been achieved and become one into consideration for students to optimizing their attempt and effort to graduate with good grades. The purpose of this research is to analyze the relation between try out and CBT of UKMPPD results. This type of research is a correlation analytic with cross sectional approach. The data of this study were the test score of the try out and CBT UKMPPD in 2019 which total about 105 . The results of this study have a significant relationship with the $\mathrm{p}$ value of $0.000(<0.05)$ between the try out UKMPPD value and the CBT UKMPPD value. The strength of the correlation obtained is very strong at 0.75 and the direction is positive. This shows that there is a significant relationship between the try out UKMPPD score and the CBT UKMPPD score.
\end{abstract}

Keywords: Try Out, CBT UKMPPD, UKMPPD

Sesuai Undang-undang No 12/2012 tentang Pendidikan Tinggi, pemerintah telah melakukan upaya penjaminan mutu pendidikan tinggi dibidang kesehatan, salah satunya upaya yang dilakukan ialah penyelenggaraan uji kompetensi secara nasional. Uji kompetensi ini mulai dilaksanakan pada tahun 2007 sebagai salah satu penerapan kebijakan Undang-undang No 29 Tahun 2004 tentang Praktik Kedokteran yang dikenal dengan Uji Kompetensi Dokter Indonesia (UKDI) dan setelah mengalami beberapa perbaikan dan perubahan selama pelaksanaan, hingga saat ini uji kompetensi diganti dengan nama Uji kompetensi mahasiswa program profesi dokter (UKMPPD) yang telah terlaksana sejak Agustus 2014. ${ }^{1}$

Uji kompetensi mahasiswa program profesi dokter merupakan salah satu tahapan

Penulis korespondensi: dr.firdaus@lecturer.unri.ac.id

${ }^{1}$ KJF Pendidikan Kedokteran, Fakultas Kedokteran Universitas Riau, Pekanbaru, Riau, Indonesia

${ }^{2}$ Fakultas Kedokteran Universitas Riau, Pekanbaru, Riau, Indonesia penting bagi mahasiswa kedokteran. Pada UKMPPD seorang mahasiswa kedokteran akan dinilai akan profesionalitasnya, kemampuan komunikasi efektif, landasan ilmiah ilmu kedokteran, keterampilan klinis dan beberapa komponen lainnya. Computer Based Test (CBT) merupakan salah satu bagian ujian dalam UKMPPD. Computer based test menggunakan komputer dalam pelaksanaannya menggunakan soal dalam bentuk pilihan ganda untuk menilai tingkat pengetahuan dari peserta UKMPPD. ${ }^{2,3}$

Jumlah peserta UKMPPD tahun 2014 2017 mengalami peningkatan setiap tahunnya. Tahun 2014 terdata 3428 peserta dengan persentase kelulusan $67 \%$ dan mengalami peningkatan tahun 2017 dengan jumlah peserta 11537 dengan persentase $73 \%$. Kelulusan peserta UKMPPD di Fakultas Kedokteran Universitas Riau tahun 2014-2017 adalah 79\% dari 368 peserta yang mengikuti UKMPPD, dengan nilai retaker hingga akhir 2017 berjumlah 15 orang. ${ }^{4}$

Diantara persoalan yang dihadapi institusi institusi penyelenggara pendidikan kedokteran yaitu bertambah banyaknya peserta UKMPPD yang tidak lulus. Peserta retaker UKMPPD juga masih menjadi tanggung jawab Fakultas 
Kedokteran masing-masing, sehingga beberapa fakultas kedokteran berupaya meningkatkan jumlah kelulusan UKMPPD untuk mengurangi jumlah retaker. Salah satu upaya yang dilakukan oleh institusi fakultas kedokteran adalah dengan mengadakan Try out UKMPPD. Try out UKMPPD merupakan salah satu tes formatif yang wajib diikuti peserta sebelum mengikuti UKMPPD. ${ }^{4}$ Tujuan penelitian ini adalah untuk mengetahui hubungan antara nilai try out UKMPPD dan nilai CBT UKMPPD di Fakultas Kedokteran Universitas Riau.

\section{METODE}

Penelitian ini merupakan penelitian analitik korelatif dengan pendekatan cross sectional. Pada penelitian ini dilakukan analisis hubungan nilai try out UKMPPD dengan nilai CBT UKMPPD di Fakultas Kedokteran Universitas Riau tahun 2019. Data penelitian ini diperoleh dari data sekunder yaitu database yang didapat dari Unit Asesmen FK UNRI. Populasi penelitian adalah mahasiswa yang mengikuti try out dan mengikuti UKMPPD pada tahun 2019. Seluruh populasi pada penelitian ini menjadi sampel penelitian (total sampling). Selanjutnya data yang diperoleh dianalisis dengan menggunakan korelasi spearman. Penelitian telah mendapatkan persetujuan etik dari Unit Etika Penelitian Kedokteran / Kesehatan Fakultas Kedokteran Universitas Riau, Nomor:

B/100/UN19.5.1.1.8/UEPKK/2020.

\section{HASIL}

Mahasiswa FK Unri yang mengikuti UKMPPD pada periode Februari-Agustus 2019 berjumlah 105 orang. Tabel 1 memperlihatkan gambaran hasil rata-rata nilai Try out UKMPPD pada tahun 2019 berdasarkan sistem tubuh yang diuji.

Berdasarkan Tabel 1 diatas jumlah sistem yang diuji dalam Try out UKMPPD terdapat 14 sistem. Sistem tubuh yang mendapat nilai tertinggi yaitu terdapat pada sistem ginjal dan saluran kemih yaitu 65,19 sedangkan sistem yang mendapatkan nilai terendah yaitu musculoskeletal yaitu 50,05. Non sistem yang diuji didapatkan nilai tertinggi adalah ilmu kedokteran forensik dan medikolegal yaitu 48,89 sedangkan nilai terendah terdapat pada ilmu kedokteran penunjang praktik dengan nilai 44,47.

Tabel 1. Gambaran hasil Try out UKMPPD pada tahun 2019 berdasarkan sistem tubuh yang diuji

\begin{tabular}{lcc}
\hline \multicolumn{1}{c}{ Sistem tubuh } & $\begin{array}{c}\text { Rata-rata } \\
\text { Nilai } \\
\text { Try out } \\
\text { UKMPPD }\end{array}$ & $\begin{array}{c}\text { Batas } \\
\text { kelulusan } \\
\text { Minimal } \\
\text { UKMPPD }\end{array}$ \\
\hline Saraf & 60,79 & \\
Psikiatri & 53,92 & \\
Indra & 57,16 & \\
respirasi & 58,27 & \\
kardiovaskuler & 56,86 \\
Gastrointestinal, & 57,28 \\
Hepatobilier, dan pankreas & & \\
Ginjal dan saluran kemih & 65,19 & \\
Reproduksi & 60,12 \\
Endokrin Metabolik dan & 53,21 \\
Nutrisi & 56,6 \\
Hematologi dan Imunologi & 50,05 \\
Musculoskeletal & 55,94 \\
Integumen & \\
& \\
Non sistem & \\
Ilmu Kedokteran Forensik & 48,89 \\
dan Medikolegal & 44,47 \\
Ilmu Kedokteran Penunjang & \\
Praktik & \\
& & \\
\hline
\end{tabular}

Berdasarkan tabel 2, didapatkan sistem yang mendapat nilai tertinggi yaitu sistem integumen 85,14 sedang nilai yang terendah terdapat pada ilmu kedokteran penunjang praktik 46,61. Seluruh sistem yang diuji terdapat tiga sistem yang tidak lulus dari batas minimal kelulusan UKMPPD. Rata-rata nilai UKMPPD sudah melewati batas minimal kelulusan UKMPPD yaitu 76,26 untuk persentase yang lulus ujian UKMPPD yaitu $88,58 \%$ sedangkan yang tidak lulus yaitu $11,42 \%$.

\section{Hubungan Antara Hasil Try out Ukmppd dan Hasil UKMPPD}

Hubungan antara Hasil nilai Try out dan nilai UKMPPD dapat dilihat pada tabel 3 berikut iniBerdasarkan tabel di atas menunjukkan rata-rata hasil try out UKMPPD adalah sebesar 56,54, sedangkan hasil nilai rata-rata CBT UKMPPD adalah sebesar 76,26. Hasil uji spearman didapatkan sig.(2-tailed) antara try out dengan UKMPPD adalah sebesar $0.000(<0.05)$ yang 
berarti terdapat korelasi yang signifikan antara variabel try out dengan UKMPPD. Koefisien korelasi dari kedua variabel tersebut adalah sebesar 0.75 yang menunjukkan kekuatan korelasi kuat.

Tabel 2. Gambaran hasil UKMPPD pada tahun 2019 berdasarkan persentase dan pembagian sistem tubuh yang diuji.

\begin{tabular}{|c|c|c|c|c|}
\hline $\begin{array}{l}\text { Sistem } \\
\text { tubuh }\end{array}$ & $\begin{array}{l}\text { Rata- } \\
\text { rata } \\
\text { nilai } \\
\text { ukmp } \\
\text { pd }\end{array}$ & $\begin{array}{c}\text { Nilai } \\
\text { rata- } \\
\text { rata } \\
\text { UKM } \\
\text { PPD } \\
\text { CBT } \\
\end{array}$ & $\begin{array}{c}\text { \% lulus } \\
\text { ujian } \\
\text { UKMP } \\
\text { PD } \\
\text { CBT }\end{array}$ & $\begin{array}{c}\text { \%Tidak } \\
\text { lulus } \\
\text { ujian } \\
\text { UKMP } \\
\text { PD } \\
\text { CBT } \\
\end{array}$ \\
\hline Saraf & 77,25 & & & \\
\hline Psikiatri & 71,67 & & & \\
\hline Indra & 80,40 & & & \\
\hline Respirasi & 79,43 & & & \\
\hline $\begin{array}{l}\text { Kardiovasku } \\
\text { ler }\end{array}$ & 77,55 & & & \\
\hline $\begin{array}{l}\text { Gastrointesti } \\
\text { nal, } \\
\text { hepatobilier, } \\
\text { dan pankreas }\end{array}$ & 74,54 & & & \\
\hline $\begin{array}{l}\text { Ginjal dan } \\
\text { saluran } \\
\text { kemih }\end{array}$ & 80,60 & & & \\
\hline Reproduksi & 80,43 & & & \\
\hline $\begin{array}{l}\text { Endokrin, } \\
\text { metabolik } \\
\text { dan nutris }\end{array}$ & 65,98 & & & \\
\hline $\begin{array}{l}\text { Hematologi } \\
\text { dan }\end{array}$ & 72,13 & 76,26 & $88,58 \%$ & $11,42 \%$ \\
\hline $\begin{array}{l}\text { Imunologi } \\
\text { Musculoskel } \\
\text { etal }\end{array}$ & 79,88 & & & \\
\hline Integument & 85,14 & & & \\
\hline $\begin{array}{l}\text { Non Sistem } \\
\text { tubuh }\end{array}$ & & & & \\
\hline $\begin{array}{l}\text { Ilmu } \\
\text { kedokteran } \\
\text { forensik dan } \\
\text { medikolegal } \\
\text { ilmu }\end{array}$ & 63,49 & & & \\
\hline $\begin{array}{l}\text { Kedokteran } \\
\text { Penunjang } \\
\text { Praktik }\end{array}$ & 46,61 & & & \\
\hline
\end{tabular}

\section{PEMBAHASAN}

Merujuk dari hasil penelitian ini didapatkan sistem yang diuji pada try out UKMPPD terdapat 14 sistem. Sistem tubuh
Tabel 3. Hubungan Antara Hasil nilai Try out dan nilai UKMPPD

\begin{tabular}{lccc}
\hline & Mean & R & P \\
\hline $\begin{array}{c}\text { Nilai Try out } \\
\text { UKMPPD }\end{array}$ & 56,54 & & \\
Nilai CBT & & 0.756 & 0.000 \\
UKMPPD & 76,26 & & \\
\hline
\end{tabular}

yang mendapatkan nilai rata-rata tertinggi pada try out UKMPPD adalah sistem ginjal dan saluran kemih 65,19 dan sistem tubuh yang nilai rata-rata try out UKMPPD terendah terdapat pada sistem musculoskeletal 50,05. Pada non sistem yang mendapatkan nilai tertinggi yaitu ilmu kedokteran forensik dan medikolegal 48,49 dan non sistem yang mendapatkan nilai terendah ialah ilmu kedokteran penunjang praktik 44,47. Secara keseluruhan dari semua sistem yang diujikan kurang memuaskan yang mana lebih rendah dibandingkan dengan nilai batas minimum kelulusan UKMPPD yaitu $66 .{ }^{5}$

Pada penelitian ini didapatkan sistem yang diuji pada UKMPPD terdapat 14 sistem. Sistem yang mendapat nilai rata-rata UKMPPD-CBT tertinggi terdapat pada sistem integumen yaitu 85,14 sedangkan sistem yang mendapat nilai ratarata terendah terdapat pada ilmu kedokteran penunjang praktik yaitu 46,61. Hasil UKMPPDCBT first taker pada periode penelitian ini masih belum bagus. Hal ini karena terdapatnya tiga sistem yang tidak melewati batas nilai minimum kelulusan UKMPPD dengan membandingkan batas nilai kelulusan nasional UKMPPD tahun 2019 yaitu 66.

Persentase mahasiswa Fakultas Kedokteran Universitas Riau yang lulus UKMPPD-CBT pada tahun 2019 menunjukkan hasil yang bagus yaitu $88,58 \%$ dengan membandingkan jumlah persentase kelulusan nasional UKMPPD-CBT tahun 2019 yaitu sebesar 57,1\%. Angka persentase mahasiswa yang tidak lulus CBT UKMPPD tahun 2019 mahasiswa Fakultas Kedokteran Universitas Riau menunjukkan angka 11,42\% dimana lebih rendah dibandingkan dengan angka nasional peserta yang tidak lulus pada UKMPPD-CBT tahun 2019 yaitu sebesar 41,11\%.

Analisa hasil korelasi nilai try out UKMPPD dengan nilai UKMPPD-CBT mahasiswa Fakultas Kedokteran Universitas Riau tahun 2019 didapatkan hubungan yang signifikan dengan nilai $\mathrm{p}$ value sebesar $0,000(<0,05)$. Hasil analisa ini 
menunjukkan kekuatan korelasinya sangat kuat yaitu 0,75 dengan arah korelasinya positif. Hal ini sejalan dengan hasil penelitian Labatjo dkk menunjukkan terdapatnya korelasi yang sangat kuat antara try out dengan CBT UKMPPD dengan arah korelasi positif yang berarti semakin tinggi nilai try out maka semakin tinggi pula nilai CBT UKMPPD dan kekuatan korelasinya sangat kuat. ${ }^{6}$

Try out pada dasarnya merupakan suatu bentuk penilaian formatif sedangkan UKMPPD merupakan penilain sumatif. Penilain formatif sangat penting dalam meningkatkan hasil penilaian sumatif., ${ }^{7,9}$ Penilaian formatif membantu mahasiswa mengidentifikasi kekurangannya sehingga mahasiswa dapat memperbaikinya sebelum menghadapi ujian sumatif. ${ }^{8}$

Try out sebagai bentuk penilaian formatif berpengaruh terhadap motivasi dan prestasi mahasiswa pada ujian UKMPPDCBT. Penilaian formatif dapat berdampak kuat pada motivasi dan prestasi siswa. ${ }^{10}$ Hasil yang diperoleh mahasiswa pada try out dapat memacu semangat dalam belajar, memperbaiki kekurangan - kekurangan yang terpantau melalui hasil try out.

Try out juga mempengaruhi regulasi belajar mahasiswa. Sebagai suatu penilaian formatif, try out memberikan feedback akan pencapaian kompetensi mahasiswa berupa skor persistem yang diujikan. Hal ini akan berpengaruh terhadap pengaturan belajar mahasiswa dalam menghadapi UKMPPD. Regulasi belajar dalam prakteknya berupa pengawasan aktif dan pengaturan sejumlah proses belajar yang antara lain dapat mengacu dari tujuan ingin diraih, pengaturan sumber daya, reaksi umpan balik eksternal. ${ }^{11}$ Skor try out sendiri dapat menjadi umpan balik eksternal terhadap kesiapan mahasiswa menghadapi UKMPPDCBT.

Try out sebagai ujian persiapan dapat berpengaruh terhadap hasil yang dicapai mahasiswa pada UKMPPD-CBT. Hal ini dikarenakan ujian persiapan berpengaruh terhadap motivasi dan pengaturan belajar mahasiswa, sehingga mempengaruhi performa mahasiswa pada ujian utama. ${ }^{12,13}$ Try out memberikan gambaran pelaksanan ujian
UKMPPD CBT kepada mahasiswa, sehingga hal ini mendorong persiapan aktif oleh mahasiswa untuk menghadapi UKMPPD-CBT. Persiapan aktif mahasiswa dalam suatu proses penilaian adalah kunci sukses dalam ujian sumatif. ${ }^{12}$ Melalui try out mahasiswa akan terpapar oleh suatu tes formatif UKMPPD-CBT yang memiliki pengaruh positif. Terpaparnya mahasiswa dengan suatu tes formatif dapat meningkatan kemampuan mereka untuk mengingat kembali materi yang diajarkan dibandingkan dengan mahasiswa yang hanya mempelajari kembali atau membaca ulang materi pembelajarannya. ${ }^{14} \mathrm{Hal}$ ini dikarenakan memori manusia tidak bersifat statis, tes dapat melatih memori dan memiliki efek yang kuat dalam proses penguatan memori akan pengetahuan sebelumnya, sehingga terbentuknya memori spesifik yang lebih kuat. ${ }^{15}$

\section{SIMPULAN}

Berdasarkan hasil penelitian ini dapat disimpulkan bahwa terdapat hubungan yang signifikan antara nilai try out UKMPPD-CBT dengan hasil UKMPPD-CBT di Fakultas Kedokteran Universitas Riau tahun 2019. Try out sebagai suatu formatif / persiapan tes UKMPPDCBT perlu terus dilaksanakan dan ditingkatkan. Perlu dilakukan penelitian kualitatif lebih lanjut untuk mencari variabel - variabel yang diperlukan untuk meningkatkan lagi efektivitas Try Out.

\section{DAFTAR PUSTAKA}

1. Konsil Kedokteran Indonesia. Peraturan Konsil Kedokteran Indonesia nomor 11 tahun 2012 tentang standar kompetensi kedokteran Indonesia; 2012

2. Febrianti, Winda., Memah, Maya F, Manoppo, Firginia P. Hubungan IPK sarjana dan profesi dengan nilai CBT, OSCE dan hasil UKMPPD di Fakultas Kedokteran Universitas Sam Ratulangi periode Mei dan Februari 2017. Jurnal eBiomedik. 2017; 2(7)

3. Suswati, Rahayu. Validitas prediktif hasil belajar mahasiswa kedokteran dengan uji kompetensi mahasiswa program profesi dokter. Fakultas Kedokteran Universitas Muhammadiyah Malang. 2019. 4-9

4. Kementerian Riset, Teknologi, dan Pendidikan Tinggi. Potret pendidikan kedokteran di 
Indonesia : refleksi upaya penjaminan mutu; 2018

5. Burhanudin I, Sutrisna EM. Evaluasi ujian seleksi masuk FK UMS dan Try Out UKMPPD berdasar validitas prediktif. Prosiding Annual Meeting Asosiasi Pendidikan Kedokteran dan Kesehatan Muhammadiyah ke-V. Palembang: Universitas Muhammadiyah Palembang. Available from: http://ejournal. umm.ac.id/index.php/sainmed/article/vi ew/5553.

6. Labatjo, Atika, Manoppo, Virginia, Berhimpon, Siemona. Hubungan nilai ujian try out lokal dengan nilai Computer Based Test Uji Kompetensi Mahasiswa Program Profesi Dokter di Fakultas Kedokteran Universitas Sam Ratulangi Manado. Jurnal e-Biomedik. 2019;7(1).

7. Black P and William D. Assessment and Classroom learning. Assessment in Education. 1999; 5:103-110

8. Das, S, Alsalhanie.K, Nauhria.S, Joshi.v.k, Khan.S, Surender.V, Impact of formative assessment on the outcome of summative assessment - a feedback based cross sectional study conducted among basic science medical students enrolled in MD program. Asian Journal of Medical Sciences. 2017; 8( 4), pp 38-43.

9. Begum.N, Hossain.S, Talukder.H.K, Influence of formative assessment on summative assessment in undergraduate medical students, Bangladesh Journal of Medical Education, 2013; 4(1), 16-19.
Firdaus dkk, Hubungan Nilai Try Out

10. Cauley K and McMillan J. Formative Assessment Techniques to Support Student Motivation and Achievement. The Clearing House: A Journal of Educational Strategies, Issues and Ideas. 2010; 83(1):1-6.

11. Nicola.D.J, Dickb.D.M., Formative assessment and self regulated learning: a model and seven principles of good feedback practice. Studies in Higher Education 200631 (2), pp. 199-218

12. Lam. R, Formative Use of Summative Tests: Using test preparation to promote performance and self-regulation, Asia-Pacific Edu Res. 2013; 22:69-78.

13. Panadero, Ernesto, Broadbent, Jaclyn, Boud, Using formative assessment to influence selfand co-regulated learning: the role of evaluative judgement. European Journal of Psychology of Education. 2018 ; 34 (1) 10.1007/s10212-0180407-8.

14. Mcdaniel MA, Roediger HL III, McDermott KB (2007), 'Generalizing test-enhanced learning from the laboratory to the classroom. Psychon Bull Rev. 2007;14, pp 200-206.

15. Kornell $\mathrm{N}$ and Vaughn KE "How retrieval attempts affect learning: a review and synthesis". In: Psychology of Learning and Motivation, edited by Ross B. Cambridge, MA: Academic. 2016 